\title{
Effect of Work Safety and Health Knowledge on Construction Workers in Cawang-Tomang Cengkareng Toll Road Projects
}

\author{
Asep Setiawan', Sandy Radhitya Akbar ${ }^{1, *}$, Muhammad Rozahi Istambul' ${ }^{2}$, Yanyan Agustian', \\ Mohd Haizam Bin Mohd Saudi ${ }^{3}$
}

${ }^{1}$ Department of Civil Engineering, Widyatama University, Indonesia

${ }^{2}$ Department of Information System, Widyatama University, Indonesia

${ }^{3}$ Department of Management, Widyatama University, Indonesia

Copyright $\bigcirc 2019$ by authors, all rights reserved. Authors agree that this article remains permanently open access under the terms of the Creative Commons Attribution License 4.0 International License

\begin{abstract}
Safety at the location of road works is an important part that is often overlooked in the construction and maintenance of roads. Management of the safety of the road work location is the responsibility of the road manager. In general, knowledge about Occupational Health and Safety (OSH) is very broad, but there are several OHS components that are considered important to be used as a benchmark for understanding OSH. These components are K3 Definition and Initiation, K3 Management System (SMK3), Personal Protective Equipment (PPE), K3 Facilities and Infrastructure, OHS Risk. Research on the influence of occupational safety and health knowledge on occupational health on construction worker behavior was carried out to determine the effect of K3 knowledge variables together on the behavior of construction workers. And to know the effect of $\mathrm{K} 3$ knowledge variables partially on the behavior of construction workers. From the results of the study it can be concluded that there is a relationship or a low level of correlation between K3 Knowledge and Workers' Behavior while the value of the Determination Coefficient (adjusted $r$ square) is 0.033 which means only $3.3 \%$ of $\mathrm{K} 3$ Knowledge aspects that affect Construction Worker Behavior and the remaining $96.7 \%$ is influenced by other variables. Based on the results of the T-test calculation using the method of calculation of Multiple Linear Regression the value of $t$ count $<t$ table, there is no significant effect of K3 knowledge variables (Definition and Initiation, Management Systems, Personal Protective Equipment, Facilities and Infrastructure, Risk) jointly towards Construction Worker Behavior on the Toll Road Development Project.
\end{abstract}

Keywords OSH Management System, Determination Coefficient, Risk, T-test

\section{Introduction}

Safety at the location of construction work and road maintenance is a dangerous job. Although there is no official data on the number of accidents related to road works, it is believed that the number of accidents at the location of road works is quite high. Heavy accidents at the location of road works are often reported in newspapers. Two recent accidents occurred on the Puncak - West Java route. A traffic guide is hit by a truck and dies while on duty. In another accident in a bridge maintenance project, five people were hit by an overloaded vehicle. Various studies abroad show that the risk of accidents with heavy or fatal casualties is three times higher than when there is road work. Therefore, many countries impose tougher sanctions for traffic violators at the location of road works.

In general, knowledge about Occupational Health and Safety (OSH) is very broad, but there are several OHS components that are considered important to be used as a benchmark for understanding OSH. These components are K3 Definition and Initiation, K3 Management System (SMK3), Personal Protective Equipment (PPE), K3 Facilities and Infrastructure, OHS Risk. Useful definitions and initiations for the initial description of OSH in a construction project that is closely related to general recognition such as definitions of terms, abbreviations of abbreviations, meanings and meanings of OSH symbols, involved organizational structures, internal and external parties related to functions implementation of $\mathrm{K} 3$, and so on. The SMK3 process uses the PDCA (Plan Do Check Action) approach, which starts from planning, implementing, checking, and remedial actions. Thus, the 
SMK3 will run continuously as long as the organization's activities are still ongoing. Protection of workers' safety and security in a construction activity should be carried out seriously through various means to reduce the source of danger by using personal protective devices. But in the realization of the use of Personal Protective Equipment (PPE) is still very difficult, considering the workers will assume that this tool will interfere with work. Likewise with adequate $\mathrm{OHS}$ facilities and infrastructure, such as the availability or absence of MCK facilities, organic or inorganic bins, waste management, which can indirectly also influence the behavior of workers while working. Another important component is OHS risk, which describes the magnitude of potential hazards in construction work to cause incident or injury to workers which is determined by the likelihood and severity of the construction, so it must be managed and avoided through good OHS management. In this writing, the author takes the object of research on the Periodic Maintenance Project on the Cawang-Tomang Cengkareng Toll Road in 2017.

\section{Literature Review}

There are 8 principles of OSH that form the basis of $\mathrm{K} 3$ development [1], namely:

1. $\mathrm{K} 3$ is moral or ethical responsibility (Safety is an ethical responsibility).

2. $\mathrm{K} 3$ is a culture, not just a program (Safety is a culture, not a program).

3. $\mathrm{K} 3$ is the responsibility of management (Management is responsible).

4. Workers must be educated to work safely (Employees must be trained to work safety).

5. $\mathrm{K} 3$ is a reflection of labor conditions (Safety is condition of employment).

6. All preventable accidents (All injuries are preventable).

7. The K3 program is specific (Safety programs must be site specific).

8. K3 is good for business (Safety is good business).

Occupational Safety and Health (K3) must be managed as with other aspects of the company such as operations, production, logistics, human resources, finance and marketing. The OSH aspect will not work as it is without management intervention in the form of a planned effort to manage it. Therefore, $\mathrm{K} 3$ experts since the beginning of the 1980 s sought to convince all parties, especially the management of the organization to put the $\mathrm{K} 3$ aspect on par with other elements in the organization. This is what encourages the birth of various concepts regarding K3 Management (safety management). All K3 management systems aim to manage the risk of occupational safety and health in the company so that unwanted events that can cause harm can be prevented. Managing OSH is the same as managing other aspects of the company by using a modern management approach starting from planning, organizing, implementing and supervising.

Furthermore, the International Labor Organization (ILO) issued guidelines for the K3 Management System for use in the work environment. The same thing also happened in other industry sectors so that a variety of safety management systems such as Food Safety Management System, Railway Safety Management System, Marine Safety Management System, Road Safety Management System, Construction Safety Management System, Hospital Safety Management System, and others. These factors, among others, led to the birth of the OHSAS 18001 K3 management system.

K3 Management System is part of the overall management system which includes the organizational structure, planning, responsibilities, implementation, procedures, processes and resources needed for the development, implementation, achievement, assessment and maintenance of occupational health and safety policies in risk control relating to work activities in order to create a safe, efficient and productive workplace [2].

SMK3 is a systematic and comprehensive concept of K3 management in an integrated management system through the process of planning, implementing, measuring and monitoring. The SMK3 approach has developed since the 1980s, which was pioneered by K3 experts such as James Tye from the British Safety Council, Dan Petersen, Frank Birds and others. At present there are various forms of SMK3 that have been developed by various institutions at home and abroad. for example: the Five Star Management System of the British Safety Council, developed by K3 institutions in the UK around 1970; Occupational Safety and Health Management System (OHS), OHSA, USA; K3 Management System from the Indonesian Ministry of Manpower. This system has been developed in Indonesia and implemented by various companies. The audit was conducted through Sucofindo.

All of these SMK3 have in common, based on modern management processes and functions. What is different is the element of implementation that is tailored to the needs of each.

The various objectives of the SMK3 can be classified as follows:

1. As a measure of OHS performance in the organization

2. As a guideline for $\mathrm{K} 3$ implementation in organizations

3. As a basis for awards

4. As certification

Given the large number of SMK3 developed by various institutions, standardization and certification are needed. From here a K3 performance assessment called OHSAS 18000 (Occupational Health and Safety Assessment Series) was born which was first introduced in 1999 and then refined in 2007 and approved as a K3 Management System Standard. OHSAS 18000 consists of two parts, namely 
OHSAS 18001 as a standard or requirement for SMK3, and OHSAS 18002 as a guide for its development and application.

Management systems are a set of interrelated elements to establish policies and objectives to achieve this goal [3]. SMK3 consists of two main elements, namely the management process and its implementation elements. The SMK3 process explains how the management system is run or moved. While elements are key components that are integrated with each other to form an integrated management system.

These elements include, inter alia, responsibilities, authority, relationships between functions, activities, processes, practices, procedures and resources. This element is used to determine OSH policy, planning, goals, and K3 programs. The SMK3 process uses the PDCA approach (Plan - Do - Check - Action), which starts from the planning, implementation, checking, and corrective actions. Thus, SMK3 will continue continuously as long as the organization's activities are still ongoing.

SMK3 starts with determining the OSH policy by top management as a manifestation of management's commitment to support the implementation of K3. The $\mathrm{OSH}$ policy was further developed in planning. Without good planning, the $\mathrm{K} 3$ process will get lost, inefficient, and ineffective. Fig. 1 shows the Management Cycle.



Figure 1. Management Cycle

Understanding the concept of risk extensively, will be an important basis for understanding risk management concepts and techniques. Therefore, by studying various definitions of risk, it is expected that understanding the concept of risk will become clearer.

The aim of the $\mathrm{K} 3$ effort is to prevent accidents caused by hazards in the work environment. Therefore the development of SMK3 must be based on risk control in accordance with the nature and conditions of the existing hazards. Even extreme can be said that $\mathrm{K} 3$ is not needed if it is not a source of danger that must be managed. The presence of danger can result in accidents or incidents that affect humans, equipment, materials and the environment [4]. Risk describes the magnitude of potential hazards that can cause incidents or injuries to humans that are determined by the likelihood and severity produced. These hazards and risks must be managed and avoided through good OHS management [8].
To change the $\mathrm{K} 3$ culture can be done by changing the mindset of the workers. Change in mindset can be done from changing behavior. What is the relationship between mindset and behavior? Behavior is an action that can be observed or seen. Everything that is done by someone who can be seen, felt, and heard. Therefore, behavior can be measured so that it can be managed and improved. The overall management system will influence the behavior of workers. It is undeniable that the behavior that impacts the loss is unconscious behavior and occurs in a very fast time.

Why to change $\mathrm{K} 3$ culture needs to focus on behavior? From the results of the analysis of several incidents, it was concluded that $95 \%$ of work accidents directly related to behavior did not survive shortly before the occurrence of work accidents. Behavior can be observed and measured. Incidents occurs due to a combination of several behaviors. For example, from a scaffold structure, the toe board is removed to move some material. After the transfer of the material is complete, the toe board is not returned to its original place. A brick fell and struck a worker who was working under a scaffold and died. It only needs one of the behaviors - visible and measurable behavior is carried out safely to prevent accidents.

\section{Methodology}

\subsection{Population}

Population is the whole of the object of research which can be in the form of humans, animals, plants, air, symptoms, values, events, attitudes of life, etc., so that these objects can be a source of research data [5].

Population is a generalization area consisting of objects / subjects that have certain quantity and characteristics determined by researchers to be studied and then drawn conclusions [6].

\subsection{Sampling}

Sampling technique is a technique for determining the number of samples used in the study.

Sampling technique is a sampling technique, which is a sampling technique that provides equal opportunities for each element or member of the population to be selected as a sample member.

While the type of sampling technique used in this study one of which is simple random sampling. Simple random sampling is the process of selecting a sample in a certain way in which there are all elements in the population that are defined as having equal, free, and balanced opportunities selected into the sample. Given the number of population known, the sample determination formula used is "simple random sampling", with the following formula:

$$
n=\frac{\mathrm{N}}{1+\mathrm{N} e 2}
$$


Note:

$\mathrm{n}=$ sample size

$\mathrm{N}=$ population size

$\mathrm{e}=$ the level of error in reaching the member of the sample that was sampled (the error rate taken in this sampling is $10 \%$ )

\subsection{Validity Test}

Before processing data, the data collected through questionnaires were tested through data testing, namely validity and reliability testing. In order for the process of testing and processing data to be carried out quickly and accurately, data processing uses computer facilities, namely the SPSS program application.

Validity indicates the extent to which the measuring instrument measures what you want to measure, or the extent to which the measuring instrument is used on the target. The higher the validity of a test tool, the more it is about the target, or the more it shows what should be measured. This is done to find out which questions are valid and which are invalid [9][10].

"Items that have a positive correlation with criteria (total score) and high correlation, indicate that the item has a high validity as well. If the measuring instrument is $<0.3$ (invalid) and $>0.3$ (valid) ". To test the validity of the item, the SPSS program is used.

Statistical testing follows criteria:

1. $r$ count $<$ critical $r$ is invalid

2. $\quad r$ count $>r$ critical then valid

\subsection{Test Reliability}

Reliability is an index that shows the extent to which a measuring device can be trusted or reliable. Based on this definition, reliability can be interpreted as a characteristic related to accuracy, accuracy and consistency [11][12].

This test is carried out on questions that are included in the valid category. Reliability testing used in this study is with internal consistency, which is done by testing the instrument once, then analyzed using a reliability calculation technique. The technique used to test the reliability of the questionnaire in this study is the split-half method of Spearman-Brown with the following steps:

1. Divide the question into two, namely odd and even items.

2. Scores for each question in each hemisphere are summed to produce two total scores for each respondent.

3. Correlate the total score of one with a total score of two with Sperman rank correlation.

4. Look for reliability for the whole question with the Spearman Brown formula.

The spearman brown formula is as follows:

$$
r_{x y}=\frac{2 r_{b}}{1+r_{b}}
$$

Note:

$\mathrm{ri}=$ internal reliability of all instruments

$\mathrm{rb}=$ Spearman rank correlation between the first hemisphere and second.

Data processing uses computer facilities, namely the SPSS Version 20 program application.

\subsection{Methodological Approach}

The research approach used in this study is qualitative research which is a method that seeks to collect data that is appropriate to the actual situation, presents and analyzes it so that it can provide a clear enough picture of the object under study. Qualitative methods can be meaningful if the data obtained is more complete, more profound, and credible so that the research objectives are achieved. This method is appropriate to be used to examine the status of a group of people, the company as the object of research, which aims to make a systematic, factual and accurate description of the facts and the relationship between the phenomena investigated. Cengkareng in 2017. Workers' population in the Cawang-Tomang Cengkareng Toll Road Construction Project 137 people. In this study, the sampling technique was carried out by incidental sampling method. Questionnaire distribution techniques involved in toll road development projects to disseminate questionnaires, or distribute directly to construction workers on the project who are ready to work together and be used as data sources. The number of workers sampled was 137 people

To get the final goal of the research, the data needed are primary data and secondary data.

1. Primary data

That is data obtained from respondents by distributing questionnaires and or direct interviews with construction workers who are willing to be used as research samples. The primary data used is the results of questionnaire answers which are then made tabulation of respondents' answers.

\section{Secondary data}

Secondary data was obtained from PT. Hutama Karya such as general project data, RK3K Project, data on the number of workers, as well as literature and media related to the object under study.

\subsection{Variable Operational Definition}

Variables that are variable symptoms can be in the form of factors that affect other variables. Variables identified in the K3 knowledge relationship and the behavior of construction workers include: independent variables and dependent variables.

Independent variables are variables that affect other variables or variables called predictor variables. In this study as an independent variable is knowledge about $\mathrm{K} 3$ which consists of: Definition or Initiation of K3 (X1), K3 
Management System (X2), Self Protective Equipment Mechanism (X3), K3 Facilities and Infrastructure (X4), K3 Risk (X5).

Dependent variables are variables that are influenced by independent variables. The dependent variable in this study is Construction Worker Behavior (Y). In accordance with the purpose of writing, the variables to be tested are taken from the concept of variables that can influence the behavior of construction workers in the Toll Road Development Project. Variables that will be analyzed are divided into six groups, namely:

a. Variable Construction Worker Behavior (Y).

b. Variable Definition and Initiation of K3 (X1).

c. K3 Management System Variables (X2).

d. Variable Mechanism of Personal Protective Equipment (X3).

e. K3 Facility and Infrastructure Variables (X4).

f. Risk Variable K3 (X5).

In this study, the method used to collect data is as follows:

\section{a. Secondary Data Collection}

Collecting data on the number of workers involved, K3 Contract Plans, tool box meetings on toll road projects, print media relating to toll road projects, several references to research results and several other data related to Quality Control and Environmental K3 (PSMK3L).

b. Primary Data Collection

Primary data is collected by questionnaire distribution method where respondents will be asked to answer questions, which will then make a tabulation of respondents' assessments.

All variables used in this study were measured using a Likert Scale. In this case the author assumes that the Likert scale produces variable measurements in the Interval Scale. There are five measurement alternatives used, namely the Likert Scale type with a score:

$$
\begin{aligned}
& 5=\text { Very Important } \\
& 4=\text { Important } \\
& 3=\text { Medium } \\
& 2=\text { Not Important } \\
& 1=\text { Very Not Important }
\end{aligned}
$$

\section{Result and Analysis}

Based on the table.1, there is a correlation or relationship between K3 Knowledge and Worker Behavior that is equal to $0.262(>0)$. While the influence of the dependent variable on the independent variable, indicated by the coefficient of determination that has been adjusted that is equal to $0.033(3.3 \%)$. This shows that only $3.3 \%$ of the contribution of influence is given K3 knowledge factors to the behavior of workers.
Table 1. Corelation \& Determination Index

\begin{tabular}{|l|l|}
\hline \multicolumn{2}{|c|}{ Regression Statisyics } \\
\hline Multiple R & 0.262 \\
R Square & 0.068 \\
Adjusted R Square & 0,033 \\
Standard Erros & 0.736 \\
Observatios & 137 \\
\hline
\end{tabular}

Source: Excel Regression Analysis Data

From table. 1 it can be seen that $3.30 \%$ of the diversity that occurs in the variable Worker Behavior can be predicted from a combination of variables Definition and Initiation, Management Systems, Personal Protective Equipment, Infrastructure, and Risk

While the rest is explained or influenced by other variables. The calculation method used to determine the results of the calculation of K3 Knowledge Effect on Construction Worker Behavior together is the Multiple Linear Regression Analysis method with the help of Microsoft Excel software programs and SPSS programs. The steps in this method are by calculating the constant and regression coefficients, Test-F, Test-t, determining the correlation coefficient and determination.

\section{Conclusions}

From the research above it can be concluded that [7] [8]:

The value of the Correlation Coefficient (r) is 0.262 and based on the interpretation of the correlation value coefficient is between $0.200-0.399$, meaning that there is a low correlation or level of correlation between $\mathrm{OSH}$ Knowledge and Worker Behavior. While the value of the Determination Coefficient (adjusted $r$ square) is 0.033 , which means only $3.3 \%$ of the K3 Knowledge aspects that affect Construction Worker Behavior and the remaining $96.7 \%$ is influenced by other variables

Based on the results of the T-test calculation using the method of calculation of Multiple Linear Regression the value of $t$ count $<\mathrm{t}$ table, there is no significant effect of $\mathrm{K} 3$ knowledge variables (Definition and Initiation, Management Systems, Personal Protective Equipment, Facilities and Infrastructure, Risk) jointly towards Construction Worker Behavior. on the Toll Road Development Project.

\section{REFERENCES}

[1] Ramli, Soehatman, "Sistem Manajemen Keselamatan \& Kesehatan Kerja OHSAS 18001", Jakarta: Dian Rakyat, 2010, pp. 25

[2] Keputusan Mentri Tenaga Kerja 05," Sistem Manajemen Keselamatan dan Kesehatan Kerja", Jakarta, 1996. 
[3] OHSAS 18001 "Occupational Health and Safety Management Systems-Requirements”, UK, 2007

[4] Ahmed, U., Zin, M. L. M., \& Majid, A. H. A. (2016). Impact of Intention and Technology Awareness on Transport Industry's E-service: Evidence from an Emerging Economy. Journal of Industrial Distribution \& Business Vol, 7(3), 13-18.

[5] Ramli, Soehatman, "Sistem Manajemen Keselamatan \& Kesehatan Kerja OHSAS 18001", Jakarta: Dian Rakyat, 2010, pp. 30

[6] Hashimova, K. K. (2018). Creation of Algoritms for Recommendation System Based on Users Data on Internet Advertisement Marketing. Review of Information Engineering and Applications, 5(2), 41-48.

[7] Ali, A., \& Haseeb, M. (2019). Radio frequency identification (RFID) technology as a strategic tool towards higher performance of supply chain operations in textile and apparel industry of Malaysia. Uncertain Supply Chain Management, 7(2), 215-226.

[8] Ozuomba, S., Enyenihi, J., \& Rosemary, N. C. (2018). Characterisation of Propagation Loss for a $3 \mathrm{G}$ Cellular Network in a Crowded Market Area Using CCIR Model. Review of Computer Engineering Research, 5(2), 49-56.

[9] Sugiyono, "Metodologi Penelitian Bisnis", Jakarta, 2004, pp. 72

[10] Jabarullah, N.H., Shabbir, M.S., Abbas, M., Siddiqi, A.F. \& Berti, S. (2019). Using random inquiry optimization method for provision of heat and cooling demand in hub systems for smart buildings, Sustainable Cities and Society, 47, 101475.

[11] Suryanto, T., Haseeb, M., \& Hartani, N. H. (2018). The Correlates of Developing Green Supply Chain Management Practices: Firms Level Analysis in Malaysia. International Journal of Supply Chain Management, 7(5), 316.

[12] Mostofi, A., \& Erfanian, H. (2018). Multi-Shuttle Automated Storage and Retrieval System. Review of Industrial Engineering Letters, 4(1), 12-20. 